\title{
The strategic effect of bundling: a new perspective*
}

\author{
Andrea Mantovani ${ }^{\dagger}$
}

\begin{abstract}
This paper investigates the strategic effect of bundling when a multi-product firm producing two complements faces competition in both markets. I consider a demand structure where both Cournot and Bertrand competition can be evaluated. Bundling is completely ineffective when firms compete in quantities. On the contrary, under Bertrand competition, selling the two goods in a package is profitable when the goods produced by the rivals are perceived as close substitutes to those produced by the multi-product firm. Bundling drives prices up, and not only consumer surplus, but also social welfare shrinks, thus calling for the intervention of the antitrust agency.
\end{abstract}

Keywords: Bundling, Oligopoly, Bertrand competition, Social Welfare.

JEL Classification: D43, L13; L41.

${ }^{*}$ I am grateful to Elena Argentesi, Emanuele Bacchiega, Luca Lambertini, Alfredo Minerva, Arsen Palestini, Anna Socha and the audience at University of Bologna, Universitat Autònoma de Barcelona, Universitad de Alicante, Third Workshop on Game Theory in Marketing (HEC Montréal, 2009), UECE Lisbon Meetings 2009: Game Theory and Application (ISEG-Technical University of Lisbon, Lisbon, 2009) for precious comments and discussion. The usual disclaimer applies.

${ }^{\dagger}$ Department of Economics, University of Bologna; Strada Maggiore 45, 40125, Italy. Tel: +390512092602 , fax: +390512092664. Email: a.mantovani@unibo.it 


\section{Introduction}

Product bundling consists of selling two or more products in a package, or bundle. Initially, commodity bundling, like other forms of tying, has been mainly viewed as a price discrimination tool used by a monopolist to extract a larger portion of the consumer surplus, as pointed out by Stigler (1968), Adams and Yellen (1976), Schmalensee (1982 and 1984), McAfee et al. (1989) and Bakos and Brynjolfsson (1999), inter alii. When consumers have different tastes for several products, a monopolist may bundle to reduce such heterogeneity in valuations, thus earning a higher profit. This is particularly evident when the bundled goods have a negative correlation in value.

More recently, the focus has shifted to the study of multi-product firms that enjoy monopoly power only in their primary market, while still facing competition in a secondary one. It is usually analyzed the simple case where firm 1 is the sole producer of good $A$, while good $B$ is produced by both firm 1 and firm 2 . Under this very simple framework, two rich but different streams of literature emerged: one studying bundling as a powerful entry-deterrence device, the other stressing on the strategic incentives to bundle in oligopoly models.

On the one hand, the entry-deterrence effect of bundling relies on the so-called leverage theory. As initially demonstrated by Whinston (1990), a firm with monopoly power in one market can use the leverage provided by that market to foreclose the access of a rival in a second market. He specifically refers to the role of tying as a credible commitment against the potential entry of a rival in one sector and such strategy is profitable only if it succeeds. The entry-deterrence use of bundling complement goods has been further investigated by Choi and Stefanadis (2001) and Carlton and Waldman (2002). Nalebuff (2004) considers a multiproduct firm with market power in two goods and demonstrates that bundling is not only a credible tool to protect both markets from entry, but it also reduces the profit loss if entry occurs, or if there is already an existing one-product rival. Similar results are obtained by Choi (2004), who builds a deterministic R\&D model with horizontal product differentiation to analyze the effects of bundling on R\&D incentives. He finds that bundling can be beneficial even when it does not force the exit of the rival.

On the other hand, the strategic effect of bundling has been initially examined in the contributions of Carbajo et al. (1990) and Martin (1999). The bottom line is that bundling can be used by the multi-product firm to increase product 
differentiation and/or change the substitution relationship between goods $A$ and $B$. In particular, Carbajo et al. (1990) showcase the product differentiation effect in a model with homogeneous goods in market $B$ and valuations for goods $A$ and $B$ that are perfectly correlated and uniformly distributed across consumers. They evaluate the profitability of bundling both under Bertrand and Cournot competition. When firms compete in prices bundling softens market competition and both firms gain from such decision; when they compete in quantities, on the contrary, the bundling firm is the only one that gains. Martin (1999) uses a simple model of consumer behavior and derives demand curves when bundling occurs; he shows the change in substitution relationships between the goods among which consumers choose brought by bundling. His methodology can be applied only to a Cournot setting, where he demonstrates that the multi-product firm has always a strategic incentive to bundle as this operation increases its profits while reducing that of the rival.

An alternative approach in which bundling is used as a device to segment the market and relax price competition can be found in Chen (1997), who models the choice of bundling by two rival firms competing in the same markets. In particular, the two firms already produce a homogeneous good and have to decide whether to introduce a second good bundled with the former. He shows that bundling emerges as an equilibrium strategy for both firms given that it increases product differentiation. Gans and King (2006) model the interaction between four producers of two products to investigate the consequences of bundled discount to encourage customer loyalty. They found that, even for unrelated products, a bundled discount has the effect of tying customers to particular product brands, thus improving the profitability of the firms involved.

Another related field of study focuses its attention on the combination of complementary components into composite systems. Matutes and Regibeau (1988 and 1992) and Economides (1989) consider fully integrated firms and show that they prefer compatibility over incompatibility. Farrell, Monroe and Saloner (1998), on the contrary, demonstrate that firms may prefer incompatibility with cost heterogeneity in presence of at least three different varieties of each component. Denicolò (2000) analyzes compatibility and bundling choices when one generalist firm offers both components of a system and competes against two specialist firms each supplying only one component. He shows that incompatibility or pure bundling may be profitable for the generalist firm when one component is less differentiated than the other. Furthermore, in his model one of the specialist firm may lose when the generalist opts for bundling. 
A very interesting question is whether bundling should or should not be allowed by the antitrust authority. Notwithstanding its potential anti-competitive effect, most of the aforementioned literature paid relatively scarce attention to the welfare implications of bundling. ${ }^{1}$ Relevant exceptions are Chen (1997) and Martin (1999), who demonstrate the negative impact of bundling on overall social welfare. A contribution with a direct reference on antitrust decisions is the one by Choi (2008), who examines mergers in complementary system markets where the merging parties may engage in bundling. ${ }^{2}$ He shows that bundling may have both pro-competitive and anti-competitive effects; in case of any foreclosure of rivals, however, bundling reduces unambiguously social welfare and the merger should be prohibited.

The aim of my paper is to shed light on a partially neglected aspect of bundling. First, I want to demonstrate that the strategic effect of bundling applies also to the case of a multi-product firm which produces complement goods and competes with single-product rivals, each producing a horizontally differentiated versions of its products. Second, I want to investigate the consequences of bundling for social welfare, and draw policy implications. In particular, differently from previous contributions, I want to study whether the multiproduct firm may have an incentive to offer pure bundles at prices which are not lower than the sum of the prices of the two individual goods. This could be of great interest for the antitrust agency.

In order to accomplish my goal, I consider a situation in which there are three firms and two complement goods, $A$ and $B$. Firm 1 produces both goods, while firms 2 and 3 respectively produce a horizontally differentiated version of good $A$ and one of good $B$. Previous contributions did not distinguish between two different versions of the same type of good produced by two rival firms. The only exception is represented by Denicolò (2000), who considers an integrated firm which produces two components of a system and two rival firms, each providing a horizontally differentiated version of the two components. However, his focus is on compatibility rather than bundling, given that the two goods have to be combined together for the system to make sense. Moreover, in his model each consumer buys at most

\footnotetext{
${ }^{1}$ The Chicago School since Bowman (1957) and Posner (1976) harshly criticized any form of leverage theory, and this explains why price discrimination has been the initial focus of the economic literature on bundling. In the European competition policy, on the contrary, bundling has gained enormous prominence in a number of recent cases, e.g. GE/Honeywell, Tetra Laval/Sidel and the recent Microsoft case in which the European Commission ordered the unbundling of the Windows Media Player from Windows.

${ }^{2}$ In particular, he considers the decision of the European Commission to block on July 3, 2001, the proposed merger between General Electric and Honeywell on the basis of the possibility of bundling between GE's jet aircraft engines and Honeywell's avionics products.
} 
one system. On the contrary, I will try to keep things even more general, assuming that: (i) goods $A$ and $B$ are valuable in the eyes of a customer even if consumed independently, (ii) the combination $A-B$ produced by firm 1 is not superior to that provided separately by firms 2 and $3 .^{3}$ Apart from the asymmetry regarding the number of goods produced by firm 1 , there are no additional factors which could artificially create an incentive to bundle. The theoretical model that I will adopt may give rise to some algebraic complications and I will therefore limit my analysis to the case of pure bundling. Nonetheless, this will be sufficient to pinpoint the rationale behind the incentive to bundle.

Many real-life examples motivate my approach, especially in sectors like clothing, food, leisure time and entertainment. Starbucks sells coffee and cookies, but different versions of these goods can be separately purchased in a Illy coffee shop and at Aunt Annies's. The main production lines of Victoria's Secret are lingerie and body products; in alternative, consumers can buy different types of body products from Elisabeth Arden and of lingerie by Frederick's of Hollywood. Internet-based travel reservation websites, like Expedia or eDreams, offer vacation packages including travel and accommodation, but it is possible to book the flight directly from the company's webpage and look for accommodation in Booking.com, for example. Comcast provides both cable TV and Internet connection, whereas Dishnetwork is specialized in digital satellite television and Pacific Bell in Internet services. These are all examples of complement goods which can be consumed together, or separately, and they do not need to be purchased in pair to be of any value. Moreover, one can opt for a good produced by one brand complemented with a good produced by an alternative brand: no combination is a priori better than the other. Finally, they have been seasonally offered in bundles. An investigation of the potential consequences for consumers and social welfare would then be appropriate.

The starting point of my paper is a generalization of the model by Martin (1999). The aim is to demonstrate that a standard model of consumer behavior does not allow to capture the strategic effect of bundling when one introduces competition on both markets served by the multi-product firm. Moreover, Martin does not distinguish between different versions of the same product, thus limiting the possibility to extend his analysis into the directions that I want to explore. Martin's modeling strategy is nonetheless very useful as I will adopt a similar methodology when

\footnotetext{
${ }^{3}$ This is justified by the fact that recent decisions taken by the Antitrust agencies impeded the producer to bundle two complements that are mutually dependent. This is particularly true in hi-tech sectors, such as computers (see the Microsof case).
} 
rewriting the welfare function in terms of bundles.

In order to pursue the scope of my research I will have to consider a specific social welfare function that accounts for the presence of four goods in the market and derive the demand functions for both Cournot and Bertrand competition. Then I will compute the equilibrium profits for the three firms in the two alternative scenarios, depending on the decision of the multi-product firm to bundle its products or not; such decision is taken before prices or outputs are chosen. As there are no additional assumptions regarding both consumer preferences and the structure of the firms, whenever the firm will decide to bundle, it will act only on the basis of strategic considerations.

The main results of my analysis can be summarized as follows. First, when firms compete à la Cournot, the multiproduct firm does not earn additional profit by bundling. I will demonstrate that the optimal bundle consists in one unit of both products, and this helps explaining the lack of incentive to sell both goods in a package: the demand structure adopted allows the consumer to decide upon any amount of the four goods, and a 1-1 bundle is ineffective when firms set quantities. The outcome will be different under Bertrand competition, even when considering bundling on a $1-1$ ratio. When firms set prices, bundling is profitable for relatively high values of product substitutability between the different versions of goods $A$ and $B$ combined with relatively low values of product complementarity between any $A$ and $B$. This is due to the fact that the negative effect on the profit of the multi-product firm induced by (i) a lower degree of product differentiation between its varieties and the one produced by the rivals and/or (ii) a decrease in product complementarity is dampened by selling the two goods together.

Bundling acts therefore not only as a product-differentiation device, as in previous contributions, but also as a way to oblige consumers to buy both goods even when the perceived degree of complementarity is low. In my model bundling results from an accurate evaluation of the substitutability/complementarity relationships which affect the strategy of a multi-product firm which competes with alternative producers in each segment of its product line.

When bundling occurs, market competition is weaker and all firms can charge higher prices. ${ }^{4}$ However, the rivals of the multi-product firm do not always gain when bundling occurs. In particular, they incur a profit loss when product substitutability

\footnotetext{
${ }^{4}$ Based on this result, my paper contributes to the literature on 'Co-opetition', initially developed by Brandenburger and Nalebuff (1996). In a recent paper, Casadesus-Masanell et al. (2008) contribute to this literature by presenting Intel and Microsoft as a motivating example on the tension between cooperation and competition that characterizes relationships between complementors.
} 
is not sufficiently high (and/or, product complementarity is not sufficiently low), due to a reduction in the output level that is not compensated by the higher prices charged under bundling.

Another interesting result is that the multi-product firm sells the bundle at a price which is higher than the sum of the prices it charged for the individual goods. In the literature, a form of bundling in which the bundle price is higher than the sum of separate prices is known as 'premium bundling' (since Cready, 1991) and quotes as examples the collection sets, where the complete set is usually more expensive than the sum of individual components of the set. However, the explanation for such pricing policy relies on the lack of information of customers, which are not well informed about a product, or do not want to waste time in looking for the individual components and put them together. ${ }^{5}$ In my paper, on the contrary, the higher prices are due to pure strategic reasons.

Finally, I will evaluate the effects on social welfare of the decision to bundle by the multi-product firm. As prices rise and overall quantity shrinks, it will be immediate to conclude that consumer surplus is lower under bundling, thus justifying the intervention of a regulator particularly concerned at consumer protection. Taking into account also producer surplus, the main policy implication does not change, as it will be possible to demonstrate that the loss in consumer surplus is higher than the gain for firms. This reinforces the need for the competent authority to intervene and prohibit the bundling activity.

The paper is structured as follows. Section 2 proposes an extended version of Martin (1999) with two firms in each sector. Section 3 presents the demand structure that will be used in this paper. Section 4 proposes the Cournot case while Section 5 the Bertrand case and the welfare implications of bundling. Section 6 concludes.

\section{Preliminaries}

In this preliminary section I consider the model by Martin (1999), where the multiproduct firm has a monopoly power in the production of good $A$ whereas it competes with a rival in the production of good $B$. As introduced before, one of the main results of his paper is to show that bundling has a strategic effect because it alters substitutability relationships. The multi-product firm always gains from bundling,

\footnotetext{
${ }^{5}$ In the article "The Pros and Cons of Bundling", recently appeared in the The Harvard Business Review (February 26, 2010), Anthony Tjan writes that bundling often implies a lack of transparency for consumers. In particular, he argues that sellers can group products and services together in such a way to hides how much the customer would pay for each individual item.
} 
while the rival incurs in a profit loss. Net welfare unambiguously shrinks with bundling, thus calling for antitrust intervention.

I extend Martin's model to account for the presence of a third firm, which produces good $A$. The social welfare function is the one originally adopted by Spence (1976) and Dixit (1979):

$$
U=m+a\left(Q_{A}+Q_{B}\right)-\frac{1}{2}\left(Q_{A}^{2}+2 \theta Q_{A} Q_{B}+Q_{B}^{2}\right),
$$

where $m$ is the amount of the numeraire good, whose price is normalized to one, and parameter $\theta$ captures the degree of substitutability/complementarity between goods $A$ and $B$. When $\theta \in(-1,0)$, the two goods are complements, while when $\theta \in(0,1)$ the two goods are substitutes. For $\theta=0$ the two goods are independent in demand, while for $\theta=1$ (resp. $\theta=-1$ ) the two goods are perfect substitutes (resp. complements).

Inverse demand functions for the two goods are:

$$
\begin{aligned}
& p_{A}=a-Q_{A}-\theta Q_{B}, \\
& p_{B}=a-Q_{B}-\theta Q_{A} .
\end{aligned}
$$

One of the crucial point of Martin's analysis is that $Q_{A}$ and $Q_{B}$ represent the total quantities respectively produced of good $A$ and good $B$. In particular, he assumed that $Q_{A}$ is supplied only by the multi-product firm $1\left(Q_{A}=q_{A_{1}}\right)$, while $Q_{B}$ is supplied by both firms 1 and $2\left(Q_{B}=q_{B_{1}}+q_{B_{2}}\right)$. The extension that I initially propose consists in introducing firm 3 that produces good $A$, hence:

$$
\begin{aligned}
Q_{A} & =q_{A_{1}}+q_{A_{3}}, \\
Q_{B} & =q_{B_{1}}+q_{B_{2}} .
\end{aligned}
$$

It is worth noting that the above writing implies that the two varieties of each good are homogeneous, while in the model that I will propose in the next section firms 2 and 3 will respectively produce a horizontally differentiated version of good $A$ and of good $B$.

In order to minimize initial asymmetries among firms, the marginal cost of producing goods $A$ and $B$ is assumed to be symmetric across firms and equal to $c$. In absence of bundling, the profit functions for the three firms are:

$$
\begin{aligned}
& \pi_{1}=\left(p_{A}-c\right) q_{A_{1}}+\left(p_{B}-c\right) q_{B_{1}} \\
& \pi_{2}=\left(p_{B}-c\right) q_{B_{2}}, \\
& \pi_{3}=\left(p_{A}-c\right) q_{A_{3}} .
\end{aligned}
$$


From profit maximization, equilibrium quantity levels are: ${ }^{6}$

$$
\begin{aligned}
q_{A_{1}}^{*} & =q_{B_{1}}^{*}=\frac{a-c}{3+4 \theta+\theta^{2}} \\
q_{B_{2}}^{*} & =q_{A_{3}}^{*}=\frac{a-c}{3+\theta} .
\end{aligned}
$$

while equilibrium profits are:

$$
\pi_{1}^{*}=\frac{2(a-c)^{2}}{(1+\theta)(3+\theta)^{2}}, \pi_{i}^{*}=\frac{(a-c)^{2}}{(3+\theta)^{2}}, i=2,3 .
$$

Suppose now that firm 1 decides to bundle its products: in particular, it ties $\alpha \geq 1$ units of good $A$ to each unit of good $B$. Using a slightly different notation than Martin's, firm 1 offers the bundle $q_{A B_{1}} \equiv(\alpha, 1)$, while now firm 2 and 3 respectively offer "fictitious" bundles $q_{B_{2}} \equiv(0,1)$ and $q_{A_{3}} \equiv(1,0)$. The choice of $\alpha$ is endogenous and the timing of the game can be described as follows: in the preliminary stage firm 1 selects the amount $\alpha$, then it decides whether to bundle or not; the final stage is the Cournot game.

Under bundling, the overall quantity of both goods sold in the market is:

$$
\begin{aligned}
Q_{A} & =\alpha q_{A B_{1}}+q_{A_{3}}, \\
Q_{B} & =q_{A B_{1}}+q_{B_{2}} .
\end{aligned}
$$

We can derive the demand structure for bundles by substituting Eqs. (12) and (13) into (1), which becomes

$$
\begin{aligned}
U= & m+a\left[q_{A B_{1}}(1+\alpha)+q_{A_{3}}+q_{B_{2}}\right]+ \\
& -\frac{1}{2}\left[\left(q_{A B_{1}}+q_{B_{2}}\right)^{2}+2 \theta\left(q_{B_{2}}+q_{A B_{1}}\right)\left(q_{A_{3}}+\alpha q_{A B_{1}}\right)+\left(q_{A_{3}}+\alpha q_{A B_{1}}\right)^{2}\right]
\end{aligned}
$$

Inverse demand functions can be easily computed and are:

$$
\begin{aligned}
p_{A B_{1}} & =a(1+\alpha)-\left(1+2 \alpha \theta+\alpha^{2}\right) q_{A B_{1}}-(1+\alpha \theta) q_{B_{2}}-(\alpha+\theta) q_{A_{3}} \\
p_{B_{2}} & =a-q_{B_{2}}-(1+\alpha \theta) q_{A B_{1}}-\theta q_{A_{3}} \\
p_{A_{3}} & =a-q_{A_{3}}-(\alpha+\theta) q_{A B_{1}}-\theta q_{B_{2}} .
\end{aligned}
$$

Profit functions with bundling write:

$$
\begin{aligned}
{ }_{b} \pi_{1} & =\left[p_{A B_{1}}-(1+\alpha) c\right] q_{A B_{1}}, \\
{ }_{b} \pi_{2} & =\left(p_{B_{2}}-c\right) q_{B_{2}}, \\
{ }_{b} \pi_{3} & =\left(p_{A_{3}}-c\right) q_{A_{3}},
\end{aligned}
$$

\footnotetext{
${ }^{6}$ Second-order conditions and stabilty conditions are always met, as one can easily check.
} 
where additional subscript $b$ indicates bundling.

Profit maximization leads to optimal bundles as a function of $\alpha$ :

$$
\begin{gathered}
q_{A B_{1}}(\alpha)=\frac{(a-c)(2-\theta)(1+\alpha)}{\left[\alpha \theta\left(5-\theta^{2}\right)+\left(3-\theta^{2}\right)\left(1+\alpha^{2}\right)\right]}, \\
q_{B_{2}}(\alpha)=\frac{(a-c)\left(2-\theta-\alpha+5 \alpha \theta-2 \alpha \theta^{2}+3 \alpha^{2}-2 \alpha^{2} \theta\right)}{\left[\alpha \theta\left(5-\theta^{2}\right)+\left(3-\theta^{2}\right)\left(1+\alpha^{2}\right)\right]}, \\
q_{A_{3}}(\alpha)=\frac{(a-c)\left[3-\alpha-2 \alpha \theta^{2}+2 \alpha^{2}-\theta\left(2-5 \alpha+\alpha^{2}\right)\right]}{\left[\alpha \theta\left(5-\theta^{2}\right)+\left(3-\theta^{2}\right)\left(1+\alpha^{2}\right)\right]} .
\end{gathered}
$$

Second order conditions are always met; moreover, one can easily demonstrate that the above equilibrium quantities are always positive.

Firm 1's profit as a function of $\alpha$ becomes:

$$
{ }_{b} \pi_{1}(\alpha)=\frac{(a-c)^{2}(2-\theta)^{2}(1+\alpha)^{2}\left(1+2 \alpha \theta+\alpha^{2}\right)}{4\left[3-\theta^{2}+\alpha \theta\left(5-\theta^{2}\right)+\alpha^{2}\left(3-\theta^{2}\right)\right]^{2}},
$$

while the profit functions of firms 2 and 3 are:

$$
\begin{aligned}
& { }_{b} \pi_{2}(\alpha)=\frac{(a-c)^{2}\left[\theta+\alpha-2-\alpha \theta(5-2 \theta)-\alpha^{2}(3-2 \theta)\right]^{2}}{4\left[3-\theta^{2}+\alpha \theta\left(5-\theta^{2}\right)+\alpha^{2}\left(3-\theta^{2}\right)\right]^{2}}, \\
& { }_{b} \pi_{3}(\alpha)=\frac{(a-c)^{2}\left[2 \theta+\alpha-3-\alpha \theta(5-2 \theta)-\alpha^{2}(2-\theta)\right]^{2}}{4\left[3-\theta^{2}+\alpha \theta\left(5-\theta^{2}\right)+\alpha^{2}\left(3-\theta^{2}\right)\right]^{2}} .
\end{aligned}
$$

Focusing on ${ }_{b} \pi_{1}(\alpha)$, it possible to find three different values of $\alpha$ which maximize (24); however, the only admissible one is $\alpha=1 .^{7}$ It follows that the equilibrium profit functions in case of bundling are:

$$
{ }_{b} \pi_{1}^{*}=\frac{2(a-c)^{2}}{(1+\theta)(3+\theta)^{2}},{ }_{b} \pi_{i}^{*}=\frac{(a-c)^{2}}{(3+\theta)^{2}}, i=2,3 .
$$

By comparing (11) with (27) it becomes evident that:

$$
{ }_{b} \pi_{1}^{*}=\pi_{1}^{*}=\frac{2(a-c)^{2}}{(1+\theta)(3+\theta)^{2}}
$$

this implies that bundling does not convey any additional gain in terms of profit to the multi-product firm. I can therefore state the following:

Proposition 1 If one extends the model by Martin (1999) by considering one rival for each good produced by the multi-product firm, bundling becomes ineffective.

\footnotetext{
${ }^{7}$ Additional calcultions are available upon request.
} 
As firm 1's optimal bundle consists of one unit of each good, and since there are neither ex-ante asymmetries on the marginal costs, nor cost complementarities induced by selling the two goods in a unique package, bundling is irrelevant in a scenario where firms compete in quantities. One can observe that, if $\alpha=1$, profit functions (6-8) are equivalent to (18-19) when it comes to profit maximization. In particular, when taking F.O.C.s and simultaneously solving, the resulting equilibrium quantities are exactly the same, as one can verify by plugging $\alpha=1$ into (21-23). Another serious limitation of Martin's approach is that it allows to consider only Cournot competition. The demand structure (2-3), while being invertible, does not allow to derive the profit functions for firms competing in prices when one considers the presence of more than one firm for each good.

\section{The Model: changing the social welfare function}

In this section I move to the core of my paper and model the case of a multi-product firm that produces two complement goods and competes with single-product firms each producing a horizontally differentiated versions of the goods.

Multi-product firm 1 produces $A_{1}$ and $B_{1}$, which are complements. Firm 2 produces $B_{2}$, an horizontally differentiated version with respect to $B_{1}$, whereas firm 3 produces $A_{3}$, an horizontally differentiated version with respect to $A_{1}$. The consumer is free to buy whatever amount of the four goods; they do not have to be consumed together, nor in fixed amounts; moreover, the joint consumption of $A_{1}$ and $B_{1}$ does not represent a higher quality variant with respect to every other combination of $A$ and $B$. As the level of the demand intercept $a$ has no effect on relative prices and quantities, I normalize $a=1$.

The social welfare function that represents such consumer preferences takes the following form:

$$
\begin{aligned}
U= & m+\left(q_{A_{1}}+q_{B_{1}}+q_{A_{3}}+q_{B_{2}}\right)-\frac{1}{2}\left(q_{A_{1}}^{2}+q_{B_{1}}^{2}+q_{A_{3}}^{2}+q_{A_{3}}^{2}\right)+ \\
& -\left(\delta q_{A_{1}} q_{B_{1}}+\delta q_{A_{1}} q_{B_{2}}+\gamma q_{A_{1}} q_{A_{3}}+\gamma q_{B_{1}} q_{B_{2}}+\delta q_{B_{1}} q_{A_{3}}+\delta q_{B_{2}} q_{A_{3}}\right),
\end{aligned}
$$

where $m$ is the amount of the numeraire good, whose price is normalized to 1 , $q_{A_{1}}$ and $q_{A_{3}}$ (resp. $q_{B_{1}}$ and $q_{B_{2}}$ ) are the quantities of good $A$ (resp. $B$ ) produced by firm 1 and 3 (resp. 1 and 2). Parameter $\delta \in(-1,0)$ measures the degree of complementarity between each combination of $A$ and $B$, while $\gamma \in(0,1)$ measures product substitutability both between $A_{1}$ and $A_{3}$ and between $B_{1}$ and $B_{2}$. This is consistent with the general framework that I want to investigate. 
The implied inverse demand functions for the four goods are: ${ }^{8}$

$$
\begin{aligned}
& p_{A_{1}}=1-q_{A_{1}}-\delta\left(q_{B_{1}}+q_{B_{2}}\right)-\gamma q_{A_{3}}, \\
& p_{B_{1}}=1-q_{B_{1}}-\delta\left(q_{A_{1}}+q_{A_{3}}\right)-\gamma q_{B_{2}}, \\
& p_{B_{2}}=1-q_{B_{2}}-\delta\left(q_{A_{1}}+q_{A_{3}}\right)-\gamma q_{B_{1}}, \\
& p_{A_{3}}=1-q_{A_{3}}-\delta\left(q_{B_{1}}+q_{B_{2}}\right)-\gamma q_{A_{1}} .
\end{aligned}
$$

The above demand system can be inverted and direct demand functions are given by:

$$
\begin{aligned}
& q_{A_{1}}=\frac{(1+\gamma)\left[1+\gamma\left(p_{A_{3}}-1\right)-p_{A_{1}}\right]+(1-\gamma) \delta\left(p_{B_{1}}+p_{B_{2}}-2\right)+2 \delta^{2}\left(p_{A_{1}}-p_{A_{3}}\right)}{(1-\gamma)(1+\gamma+2 \delta)(1+\gamma-2 \delta)} \\
& q_{B_{1}}=\frac{(1+\gamma)\left[1+\gamma\left(p_{B_{2}}-1\right)-p_{B_{1}}\right]+(1-\gamma) \delta\left(p_{A_{1}}+p_{A_{3}}-2\right)+2 \delta^{2}\left(p_{B_{1}}-p_{B_{2}}\right)}{(1-\gamma)(1+\gamma+2 \delta)(1+\gamma-2 \delta)} \\
& q_{B_{2}}=\frac{(1+\gamma)\left[1+\gamma\left(p_{B_{1}}-1\right)-p_{B_{2}}\right]+(1-\gamma) \delta\left(p_{A_{1}}+p_{A_{3}}-2\right)+2 \delta^{2}\left(p_{B_{2}}-p_{B_{1}}\right)}{(1-\gamma)(1+\gamma+2 \delta)(1+\gamma-2 \delta)} \\
& q_{A_{3}}=\frac{(1+\gamma)\left[1+\gamma\left(p_{A_{1}}-1\right)-p_{A_{3}}\right]+(1-\gamma) \delta\left(p_{B_{1}}+p_{B_{2}}-2\right)+2 \delta^{2}\left(p_{A_{3}}-p_{A_{1}}\right)}{(1-\gamma)(1+\gamma+2 \delta)(1+\gamma-2 \delta)}
\end{aligned}
$$

As in previous contributions, I assume that: (i) the two goods are independent in production and there are no cost complementarities for the firm producing both goods; (ii) the unitary cost of producing one unit of each good is symmetric across firms and equal to $c$. Without loss of generality, constant unit production costs are set equal to zero, i.e. $c=0$.

Profit functions can be written as:

$$
\begin{aligned}
& \pi_{1}=p_{A_{1}} q_{A_{1}}+p_{B_{1}} q_{B_{1}}, \\
& \pi_{2}=p_{B_{2}} q_{B_{2}}, \\
& \pi_{3}=p_{A_{3}} q_{A_{3}} .
\end{aligned}
$$

Differently from the demand structure adopted by Martin (1999), I can write profit functions and then compute equilibrium profits both under Cournot and Bertrand competition. They will serve as benchmark cases against which to evaluate the profitability of bundling in both regimes. I limit my investigation to the case of pure bundling, given the complexity of the above demand structure. As usual, the decision of the multi-product firm on whether to bundle or not is assumed to take place before the market stage.

\footnotetext{
${ }^{8}$ A similar demand structure can be found in Choi (2008) and Economides and Salop (1992). However, both papers consider four composite products which are substitutes for one another.
} 


\section{Cournot Competition}

In this section I compute equilibrium quantities and profits when firms compete in quantities, first in the absence of bundling and then when firm 1 decides to sell its products $A_{1}$ and $B_{1}$ in a unique package.

\subsection{No Bundling}

When the multi-product firm does not resort to bundling, profit functions are simply obtained by substituting inverse demand functions (30-33) into (38-40). The market equilibrium when firms compete in quantities is characterized by the following F.O.C.s:

$$
\frac{\partial \pi_{1}}{\partial q_{A_{1}}}=0, \frac{\partial \pi_{1}}{\partial q_{B_{1}}}=0, \frac{\partial \pi_{2}}{\partial q_{B_{2}}}=0, \frac{\partial \pi_{3}}{\partial q_{A_{3}}}=0 .
$$

Equilibrium quantities are given by: ${ }^{9}$

$$
\begin{aligned}
& q_{A_{1}}^{C}=q_{B_{1}}^{C}=\frac{(2-\gamma)}{[4-\gamma(\gamma-2 \delta)+\delta(6+\delta)]}, \\
& q_{B_{2}}^{C}=q_{A_{3}}^{C}=\frac{(2-\gamma+\delta)}{[4-\gamma(\gamma-2 \delta)+\delta(6+\delta)]},
\end{aligned}
$$

where superscript $C$ indicates the Cournot case.

When evaluating the non-negativity of equilibrium quantities, it appears that:

Lemma 1 Equilibrium quantities under Cournot competition are positive iff: (i)

$$
\delta \geq(\sqrt{5}-3) \text {; (ii) } \delta<(\sqrt{5}-3) \text { and } \gamma>\gamma_{1}=-\delta-\sqrt{2\left(2+3 \delta+\delta^{2}\right)} .
$$

Proof See the Appendix.

I limit my attention to the interval region where quantities are positive and assume that the conditions appearing in Lemma 1 are always met. An ancillary result of Lemma 1 is the exclusion of the very peculiar case of simultaneous perfect complementarity and perfect substitutability $(\delta=-1$ together with $\gamma=1)$. In particular, when $\delta=-1$, there are no admissible values in $\gamma \in(0,1)$ that satisfy the above condition.

By plugging (42) and (43) into demand functions (30-33) and simplifying, equilibrium prices are:

$$
\begin{aligned}
& p_{A_{1}}^{C}=p_{B_{1}}^{C}=\frac{(2-\gamma)(1+\delta)}{[4-\gamma(\gamma-2 \delta)+\delta(6+\delta)]} \\
& p_{A_{3}}^{C}=p_{B_{3}}^{C}=\frac{(2-\gamma+\delta)}{[4-\gamma(\gamma-2 \delta)+\delta(6+\delta)]}
\end{aligned}
$$

\footnotetext{
${ }^{9}$ Second Order Conditions and stability conditions are always met, as it can be easily verified.
} 
which are positive in the interval region under consideration. It is relatively easy to demonstrate that $q_{A_{1}}^{C}=q_{B_{1}}^{C}>q_{B_{2}}^{C}=q_{A_{3}}^{C}$ and $p_{A_{1}}^{C}=p_{B_{1}}^{C}<p_{A_{3}}^{C}=p_{B_{3}}^{C}$ : the multi-product firm sells more of each product and charges a lower price than the rivals.

Finally, equilibrium profits in absence of bundling are:

$$
\begin{gathered}
\pi_{1}^{C}=\frac{2(2-\gamma)^{2}(1+\delta)}{[4-\gamma(\gamma-2 \delta)+\delta(6+\delta)]^{2}}, \\
\pi_{2}^{C}=\pi_{3}^{C}=\frac{(2-\gamma+\delta)^{2}}{[4-\gamma(\gamma-2 \delta)+\delta(6+\delta)]^{2}} .
\end{gathered}
$$

Obviously, as firm 1 sells both products, $\pi_{1}^{C}>\pi_{2}^{C}=\pi_{3}^{C}$; however, by comparing the profit of the multi-product firm with the sum of the profits of its rivals, we find that:

Lemma $2 \pi_{1}^{C}>\pi_{2}^{C}+\pi_{3}^{C}$ when $\gamma>\gamma_{2}=1-\sqrt{1+\delta}$, where $\gamma_{2}>\gamma_{1}$.

Lemma 2 can be illustrated with the aid of Figure A, where the above threshold values of $\gamma$ determine the partition of the parameter space represented in $\delta \in(-1,0)$ and $\gamma \in(0,1)$. The dashed area in $\gamma \in\left(0, \gamma_{1}\right)$ can be disregarded, following Lemma 1.

Figure A : Profits' comparison in Cournot competition

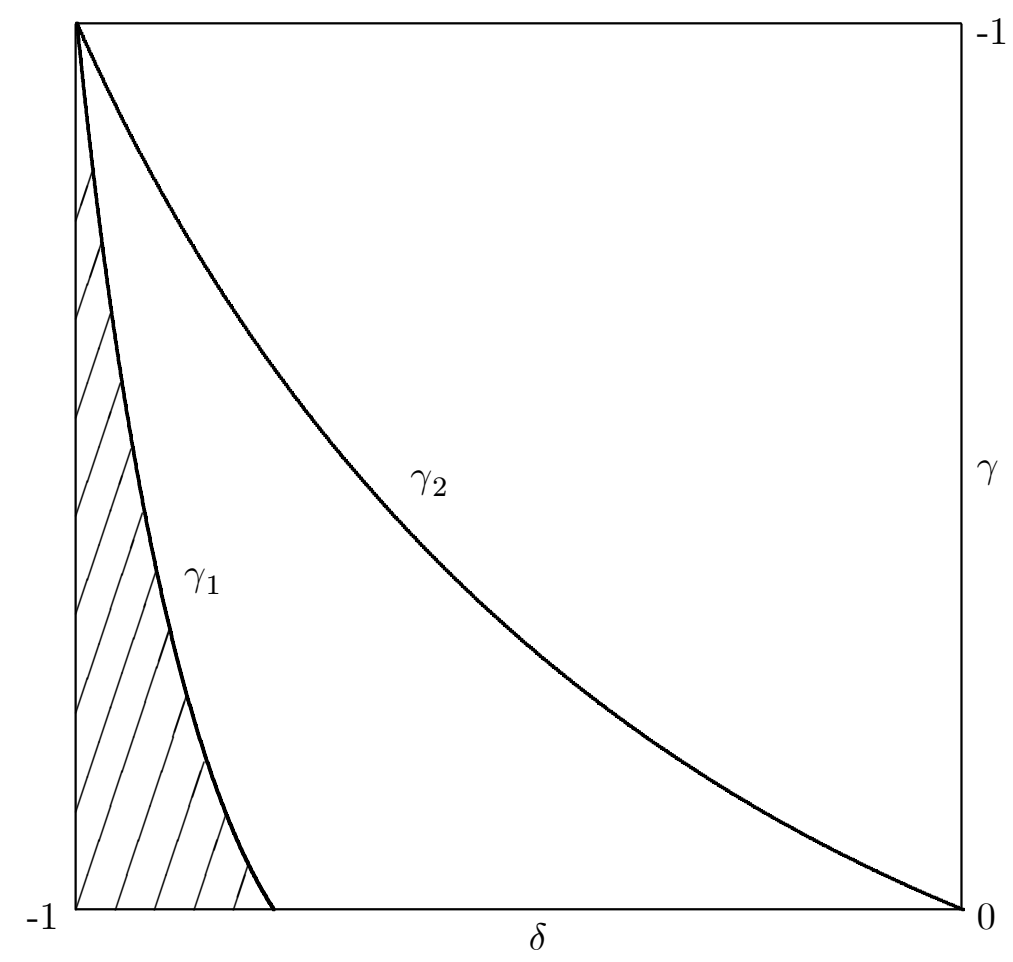


The derivatives of the equilibrium profits w.r.t. $\gamma$ convey the expected results that $\partial \pi_{1}^{C} / \partial \gamma<0$ and $\partial\left(\pi_{2}^{C}+\pi_{3}^{C}\right) / \partial \gamma<0$. However, an increase in the degree of product substitutability hits less the multi-product firm than the single-product firms, given that:

$$
\left|\frac{\partial \pi_{1}^{C}}{\partial \gamma}\right|<\left|\frac{\partial\left(\pi_{2}^{C}+\pi_{3}^{C}\right)}{\partial \gamma}\right|
$$

This result deserves an additional explanation. It has been already shown that firm 1 sells a higher amount of its variants of goods $A$ and $B$ and charges a lower price than the rivals: compared to firms 2 and 3, on each good firm 1 enjoys a quantity surplus but suffers from a price reduction. Consider the market for good $A$, for example: equilibrium prices and quantities are a negative function of product substitutability, i.e. $\partial q_{A_{1}}^{C} / \partial \gamma<0, \partial q_{A_{3}}^{C} / \partial \gamma<0, \partial p_{A_{1}}^{C} / \partial \gamma<0$ and $\partial p_{A_{3}}^{C} / \partial \gamma<0$. Moreover:

$$
\begin{aligned}
\left|\frac{\partial q_{A_{1}}^{C}}{\partial \gamma}\right| & <\left|\frac{\partial q_{A_{3}}^{C}}{\partial \gamma}\right| \text { when } \gamma+\delta>0 \\
\left|\frac{\partial p_{A_{1}}^{C}}{\partial \gamma}\right| & <\left|\frac{\partial p_{A_{3}}^{C}}{\partial \gamma}\right| \text { always in our interval region. }
\end{aligned}
$$

The same result obviously holds when considering the market for good $B$. It follows that, when product differentiation is relatively low (i.e. $\gamma$ increases), the quantity surplus expands and the price loss decreases, thus explaining the higher profit of the multiproduct firm with respect to the sum of the profits of the two single-product firms. Finally, notice that $\partial \gamma_{2} / \partial \delta<0$ : the lower the degree of complementarity between any $A$ and $B$, the higher the probability to lie in the region $\gamma>\gamma_{2}$.

\subsection{Bundling}

Consider the situation in which the multi-product firm 1 decides to tie its two products $A_{1}$ and $B_{1}$ in the bundle $q_{A B_{1}}$. Following Martin's (1999), it may offer $\alpha$ units of $B_{1}$ for each unit of $A_{1}$, or viceversa, while firms 2 and 3 respectively continue to offer goods $B_{2}$ and $A_{3}$. Consider the case in which $q_{A_{1}}=q_{A B_{1}}$ and $q_{B_{1}}=\alpha q_{A B_{1}}$. The social welfare function (29) with bundle $q_{A B_{1}}$ becomes:

$$
\begin{aligned}
U= & m+\left[q_{A B_{1}}(1+\alpha)+q_{A_{3}}+q_{B_{2}}\right]-\frac{1}{2}\left[q_{A B_{1}}^{2}(1+\alpha)+q_{A_{3}}^{2}+q_{A_{3}}^{2}\right]+ \\
& -\left[\alpha \delta q_{A B_{1}}\left(q_{A B_{1}}+q_{B_{2}}\right)+\gamma q_{A B_{1}}\left(q_{A_{3}}+\alpha q_{B_{2}}\right)+\delta q_{A_{3}}\left(\alpha q_{A B_{1}}+q_{B_{2}}\right)\right]
\end{aligned}
$$


The implied inverse demand functions for bundle $q_{A B_{1}}$ and quantities $q_{B_{2}}$ and $q_{A_{3}}$ are:

$$
\begin{aligned}
p_{A B_{1}} & =1+\alpha-q_{A B_{1}}\left(1+2 \alpha \delta+\alpha^{2}\right)-(\gamma+\delta) q_{B_{2}}-(\alpha \delta+\gamma) q_{A_{3}} \\
p_{B_{2}} & =1-q_{B_{2}}-(\alpha \gamma+\delta) q_{A B_{1}}-\delta q_{A_{3}} \\
p_{A_{3}} & =1-q_{A_{3}}-(\alpha \delta+\gamma) q_{A B_{1}}-\delta q_{B_{2}}
\end{aligned}
$$

Profit functions with bundling in Cournot competition are given by:

$$
\begin{aligned}
{ }_{b} \pi_{1} & =p_{A B_{1}} q_{A B_{1}}= \\
& =\left\{1+\alpha-q_{A B_{1}}\left(1+2 \alpha \delta+\alpha^{2}\right)-(\gamma+\delta) q_{B_{2}}-(\alpha \delta+\gamma) q_{A_{3}}\right\} q_{A B_{1}} \\
{ }_{b} \pi_{2} & =p_{B_{2}} q_{B_{2}}=\left[1-q_{B_{2}}-(\alpha \gamma+\delta) q_{A B_{1}}-\delta q_{A_{3}}\right] q_{B_{2}} \\
{ }_{b} \pi_{3} & =p_{A_{3}} q_{A_{3}}=\left[1-q_{A_{3}}-(\alpha \delta+\gamma) q_{A B_{1}}-\delta q_{B_{2}}\right] q_{A_{3}}
\end{aligned}
$$

where additional subscript $b$ indicates bundling. Taking F.O.C.s:

$$
\frac{\partial\left({ }_{b} \pi_{1}\right)}{\partial q_{A B_{1}}}=0, \frac{\partial\left({ }_{b} \pi_{2}\right)}{\partial q_{B_{2}}}=0, \frac{\partial\left({ }_{b} \pi_{3}\right)}{\partial q_{A_{3}}}=0
$$

I obtain the following equilibrium quantities as a function of $\alpha$ :

$$
\begin{gathered}
q_{A B_{1}}(\alpha)=\frac{(2-\gamma)(2-\delta)(1+\alpha)}{2\left\{4-\gamma^{2}-2 \delta^{2}+\gamma \delta+\alpha \delta\left[8-(4-\gamma) \delta-\delta^{2}\right]+(2-\gamma)\left(2+\gamma-\delta^{2}\right) \alpha^{2}\right\}} \\
q_{B_{2}}(\alpha)=\frac{(2-\gamma)(2+\gamma-2 \delta)+\alpha\left[\gamma^{2}+2(3-\delta) \delta-\gamma(2+\delta)\right]+\alpha^{2}(2-\gamma)(2-\delta)}{2\left\{4-\gamma^{2}-2 \delta^{2}+\gamma \delta+\alpha \delta\left[8-(4-\gamma) \delta-\delta^{2}\right]+\alpha^{2}(2-\gamma)\left(2+\gamma-\delta^{2}\right)\right\}} \\
q_{A_{3}}(\alpha)=\frac{\left.(2-\gamma)(2-\delta)+\alpha\left[\gamma^{2}+2(3-\delta) \delta-\gamma(2+\delta)\right]+\right) \alpha^{2}(2-\gamma)(2+\gamma-2 \delta)}{2\left\{4-\gamma^{2}-2 \delta^{2}+\gamma \delta+\alpha \delta\left[8-(4-\gamma) \delta-\delta^{2}\right]+\alpha^{2}(2-\gamma)\left(2+\gamma-\delta^{2}\right)\right\}}
\end{gathered}
$$

Second order conditions and non-negativity of equilibrium quantities are always met when Lemma 1 holds.

Firm 1's profit is given by:

$$
{ }_{b} \pi_{1}(\alpha)=\frac{(2-\gamma)^{2}(2-\delta)^{2}(1+\alpha)^{2}\left(1+2 \alpha \delta+\alpha^{2}\right)}{4\left\{4-\gamma^{2}-2 \delta^{2}+\gamma \delta+\alpha \delta\left[8-(4-\gamma) \delta-\delta^{2}\right]+(2-\gamma)\left(2+\gamma-\delta^{2}\right) \alpha^{2}\right\}^{2}} .
$$

I omit for brevity the profit functions of $B$ and $C$ and focus on ${ }_{b} \pi_{1}(\alpha)$. It is relatively easy to find three values of $\alpha$ which maximize (62); however, the only admissible solution is $\alpha=1$, as in Section $2 .{ }^{10}$

\footnotetext{
${ }^{10}$ Additional calculations are available upon request.
} 
Equilibrium profit functions for bundling when $\alpha=1$ are:

$$
\begin{gathered}
{ }_{b} \pi_{1}^{C}=\frac{2(2-\gamma)^{2}(1+\delta)}{[4-\gamma(\gamma-2 \delta)+\delta(6+\delta)]^{2}}, \\
{ }_{b} \pi_{i}^{C}=\frac{(2-\gamma+\delta)^{2}}{[4-\gamma(\gamma-2 \delta)+\delta(6+\delta)]^{2}}, i=2,3 .
\end{gathered}
$$

One can easily notice that the above expressions are exactly equivalent to (46) and (47). In particular,

$$
{ }_{b} \pi_{1}^{C}=\pi_{1}^{C}=\frac{2(2-\gamma)^{2}(1+\delta)}{[4-\gamma(\gamma-2 \delta)+\delta(6+\delta)]^{2}}
$$

as a consequence, bundling does not bring any additional profit gain for firm 1 . This implies:

Proposition 2 In a Cournot model with a multi-product firm that produces two goods and competes with a single-product firm in each market, the strategy of bundling is ineffective.

Even when the demand structure accounts for the simultaneous presence of complementarity and substitutability relationships across goods, bundling is still irrelevant when the multi-product firm competes à la Cournot with single-product rivals in each segment of the market. The bundle consists of a $1-1$ ratio and this does not change consumers' perception of the degree of substitutability between $A_{1}$ and $A_{3}$ and between $B_{1}$ and $B_{2}$, nor that of complementarity between any $A$ and $B$. This can be seen by inserting $\alpha=1$ in (52-54) and noticing that it represents a compacted version of (30-33).

Differently from Martin (1999), however, the demand structure developed in Section 3 is perfectly invertible and it is therefore possible to study what happens when considering price competition.

\section{Bertrand Competition}

In this section I consider direct demand (34-37) to compute equilibrium prices, quantities and profits when firms compete à la Bertrand. The first case is the benchmark situation in which the multi-product firm does not bundle; in the second case bundling is selected and the multi-product firm obliges consumers to buy products $A_{1}$ and $B_{1}$ together in a unique package. 


\subsection{No Bundling}

When firm 1 sells its product separately, profit functions can be derived by plugging (34-37) into (38-40). The market equilibrium when firms compete in prices is characterized by the following F.O.C.s:

$$
\frac{\partial \pi_{1}}{\partial p_{A_{1}}}=0, \frac{\partial \pi_{1}}{\partial p_{B_{1}}}=0, \frac{\partial \pi_{2}}{\partial p_{B_{2}}}=0, \frac{\partial \pi_{3}}{\partial p_{A_{3}}}=0 .
$$

Solving simultaneously the above equations yields equilibrium prices:

$$
\begin{gathered}
p_{A_{1}}^{B}=p_{B_{1}}^{B}=\frac{(1-\gamma)\left[2+\gamma(3+\gamma)-6 \delta^{2}\right]}{4-\gamma^{2}(1+\gamma)+\delta(2+\delta)(1-6 \delta)+\gamma[4+\delta(4+5 \delta)]}, \\
p_{B_{2}}^{B}=p_{A_{3}}^{B}=\frac{(1-\gamma)(1+\gamma-2 \delta)(2+\gamma+3 \delta)}{4-\gamma^{2}(1+\gamma)+\delta(2+\delta)(1-6 \delta)+\gamma[4+\delta(4+5 \delta)]}
\end{gathered}
$$

where superscript $B$ indicates the Bertrand case. When evaluating second-order conditions, together with stability conditions and non-negativity of equilibrium prices, I find that:

Lemma 3 The system is stable and equilibrium prices under Bertrand competition are positive iff: (i) $\delta \geq-1 / 2$; (ii), $\gamma>\gamma_{3}=-(2 \delta+1)$ when $\delta<-1 / 2$.

Proof See the Appendix.

I assume that the conditions appearing in Lemma 3 always hold, thus guaranteeing that all participating firms find it best to produce actively in the market. Equilibrium quantities can be obtained by plugging the above equilibrium prices into demand functions (34-37) to get:

$$
\begin{gathered}
q_{A_{1}}^{B}=q_{B_{1}}^{B}=\frac{(1+\delta)\left[2+\gamma(3+\gamma)-6 \delta^{2}\right]}{4-\gamma^{2}(1+\gamma)+\delta(2+\delta)(1-6 \delta)+\gamma[4+\delta(4+5 \delta)](1+\gamma+2 \delta)}, \\
q_{B_{2}}^{B}=q_{A_{3}}^{B}=\frac{(2+\gamma+3 \delta)\left(1+\gamma+2 \delta^{2}\right)}{\left\{4-\gamma^{2}(1+\gamma)+\delta(2+\delta)(1-6 \delta)+\gamma[4+\delta(4+5 \delta)]\right\}(1+\gamma+2 \delta)} .
\end{gathered}
$$

They are obviously always positive under the conditions specified in Lemma 3. As in Cournot case, in each market firm 1 produces more and charges a lower price than the rivals: $q_{A_{1}}^{B}=q_{B_{1}}^{B}>q_{B_{2}}^{B}=q_{A_{3}}^{B}$ and $p_{A_{1}}^{B}=p_{B_{1}}^{B}<p_{A_{3}}^{B}=p_{B_{3}}^{B}$.

Finally, equilibrium profits in absence of bundles are:

$$
\pi_{1}^{B}=\frac{2(1-\delta)(1+\delta)\left[2+\gamma(3+\gamma)-6 \delta^{2}\right]^{2}}{\left\{4-\gamma^{2}(1+\gamma)+\delta(2+\delta)(1-6 \delta)+\gamma[4+\delta(4+5 \delta)]\right\}^{2}(1+\gamma+2 \delta)},
$$


$\pi_{i}^{B}=\frac{(1-\gamma)(1+\gamma-2 \delta)\left(1+\gamma-2 \delta^{2}\right)(2+\gamma+3 \delta)^{2}\left(1+\gamma-2 \delta^{2}\right)}{\left\{4-\gamma^{2}(1+\gamma)+\delta(2+\delta)(1-6 \delta)+\gamma[4+\delta(4+5 \delta)]\right\}^{2}(1+\gamma+2 \delta)}, i=2,3$.

It is to also relatively simple to prove that, when Lemma 3 holds, $\pi_{1}^{B}>\pi_{i}^{B}$. Similarly to the Cournot case, firm 1's profit is higher than the sum of its rivals' profits for sufficiently high values of product substitutability. In particular:

Lemma $4 \pi_{1}^{B}>\pi_{2}^{B}+\pi_{3}^{B}$ when $\gamma>\gamma_{4}=\frac{3+16 \delta^{2}+\delta(3-2 \Phi)+\Phi(\Phi-3)}{3 \Phi}$, where $\Phi=\left[\delta\left(37 \delta^{2}-36 \delta-9\right)+3 \sqrt{3} \sqrt{(1+\delta)^{2}\left\{1+\delta+\delta^{2}[13+\delta(101 \delta-18)]\right.}\right]^{1 / 3}$ and $\gamma_{4}>\gamma_{3}$ in $\delta \in(-1,0)$.

Except for small numerical differences in the threshold values partitioning the relevant parameter space, both the graphical representation and the intuition behind the result of Lemma 4 replicate that of Cournot (see Figure A and Lemma 2) and are therefore omitted for brevity. Yet this confirms that, compared to its rivals, the multi-product firm is less affected by the negative impact of relatively higher levels of product substitutability and/or lower levels of product complementarity.

\subsection{Bundling}

I am now in the position to study the impact of bundling when firms compete in prices. As under Cournot competition the optimal bundle consisted in a $1-1$ offer, I consider the easy case where the bundle provided by firm 1 still consists of one unit of its variety of good $A$ tied with one unit of that of good $B$. This allows to avoid unnecessary algebraic complications and to compare the two market regimes in the simplest way. It follows that $q_{A_{1}}=q_{B_{1}}=q_{A B_{1}}$. The social welfare function (29) becomes:

$$
\begin{aligned}
U= & m+\left(2 q_{A B_{1}}+q_{A_{3}}+q_{B_{2}}\right)-\frac{1}{2}\left(2 q_{A B_{1}}^{2}+q_{A_{3}}^{2}+q_{A_{3}}^{2}\right)+ \\
& -\left[\delta q_{A B_{1}}\left(q_{A B_{1}}+q_{B_{2}}\right)+\gamma q_{A B_{1}}\left(q_{A_{3}}+q_{B_{2}}\right)+\delta q_{A_{3}}\left(q_{A B_{1}}+q_{B_{2}}\right)\right],
\end{aligned}
$$

and the implied direct demand curves are:

$$
\begin{aligned}
q_{A B_{1}} & =\frac{2(1-\gamma)-(1+\delta) p_{A B_{1}}+(\gamma+\delta)\left(p_{A_{3}}+p_{B_{2}}\right)}{2(1-\gamma)(1+\gamma+2 \delta)} \\
q_{B_{2}} & =\frac{1}{4}\left[\frac{4-p_{A B_{1}}-p_{A_{3}}-p_{B_{2}}}{(1+\gamma+2 \delta)}+\frac{p_{A B_{1}}-p_{A_{3}}-p_{B_{2}}}{(1-\gamma)}-\frac{2\left(p_{A_{3}}-p_{B_{2}}\right)}{(1-\delta)}\right] \\
q_{A_{3}} & =\frac{1}{4}\left[\frac{4-p_{A B_{1}}-p_{A_{3}}-p_{B_{2}}}{(1+\gamma+2 \delta)}+\frac{p_{A B_{1}}-p_{A_{3}}-p_{B_{2}}}{(1-\gamma)}-\frac{2\left(p_{B_{2}}-p_{A_{3}}\right)}{(1-\delta)}\right] .
\end{aligned}
$$


Profit functions under Bertrand competition and bundling of firm 1 are given by:

$$
\begin{aligned}
{ }_{b} \pi_{1} & =p_{A B_{1}} q_{A B_{1}}=p_{A B_{1}}\left[\frac{2(1-\gamma)-(1+\delta) p_{A B_{1}}+(\gamma+\delta)\left(p_{A_{3}}+p_{B_{2}}\right)}{2(1-\gamma)(1+\gamma+2 \delta)}\right], \\
{ }_{b} \pi_{2} & =p_{B_{2}} q_{B_{2}}= \\
& =\frac{p_{B_{2}}}{4}\left[\frac{4-p_{A B_{1}}-p_{A_{3}}-p_{B_{2}}}{(1+\gamma+2 \delta)}+\frac{p_{A B_{1}}-p_{A_{3}}-p_{B_{2}}}{(1-\gamma)}-\frac{2\left(p_{A_{3}}-p_{B_{2}}\right)}{(1-\delta)}\right] \\
{ }_{b} \pi_{3} & =p_{A_{3}} q_{A_{3}}= \\
& =\frac{p_{A_{3}}}{4}\left[\frac{4-p_{A B_{1}}-p_{A_{3}}-p_{B_{2}}}{(1+\gamma+2 \delta)}+\frac{p_{A B_{1}}-p_{A_{3}}-p_{B_{2}}}{(1-\gamma)}-\frac{2\left(p_{B_{2}}-p_{A_{3}}\right)}{(1-\delta)}\right] .
\end{aligned}
$$

Solving simultaneously F.O.C.s:

$$
\frac{\partial\left({ }_{b} \pi_{1}\right)}{\partial p_{A B_{1}}}=0, \frac{\partial\left({ }_{b} \pi_{2}\right)}{\partial p_{B_{2}}}=0, \frac{\partial\left({ }_{b} \pi_{3}\right)}{\partial p_{A_{3}}}=0
$$

yields equilibrium prices:

$$
\begin{aligned}
& { }_{b} p_{A B_{1}}^{B}=\frac{(1-\gamma)[4-\gamma(\gamma-2+4 \delta)-\delta(4-5 \delta)]}{2\left[2-\gamma(\gamma+2 \delta)+\delta\left(3-\delta-\delta^{2}\right)\right]} \\
& { }_{b} p_{B_{2}}^{B}={ }_{b} p_{A_{3}}^{B}=\frac{(1-\gamma)(1-\delta)(2+\gamma+3 \delta)}{2\left[2-\gamma(\gamma+2 \delta)+\delta\left(3-\delta-\delta^{2}\right)\right]}
\end{aligned}
$$

Second Order Conditions, stability requirements and non-negativity conditions of equilibrium prices are always met under the parametric restrictions reported in Lemma 3, as it can be easily ascertained. Moreover, considering (81) vs. (82):

$$
{ }_{b} p_{B_{2}}^{B}={ }_{b} p_{A_{3}}^{B}<{ }_{b} p_{A B_{1}}^{B}<{ }_{b} p_{B_{2}}^{B}+{ }_{b} p_{A_{3}}^{B} ;
$$

The price charged by firm 1 for its bundle is higher than the price for each single item produced by rivals 2 and 3, but lower than their sum.

By substituting (81) and (82) into direct demand curves and rearranging:

$$
\begin{gathered}
{ }_{b} q_{A B_{1}}^{B}=\frac{(1+\delta)[4-\gamma(\gamma-2+4 \delta)-\delta(4-5 \delta)]}{4(1+\gamma+2 \delta)\left[2-\gamma(\gamma+2 \delta)+\delta\left(3-\delta-\delta^{2}\right)\right]}, \\
{ }_{b} q_{B_{2}}^{B}={ }_{b} q_{A_{3}}^{B}=\frac{(2+\gamma+3 \delta)\left(\left[2(1+\delta)-(\gamma+\delta)^{2}\right]\right.}{2(1+\gamma+2 \delta)\left[2-\gamma(\gamma+2 \delta)+\delta\left(3-\delta-\delta^{2}\right)\right]}
\end{gathered}
$$

It is straightforward to verify that in the relevant interval region equilibrium quantities are positive and:

$$
{ }_{b} q_{B_{2}}^{B}={ }_{b} q_{A_{3}}^{B}<{ }_{b} q_{b_{1}}^{B}<{ }_{b} q_{B_{2}}^{B}+{ }_{b} q_{A_{3}}^{B} ;
$$

Together with (83), this implies that a consumer interested in buying both goods $A$ and $B$, and with no strong preference for a specific variety, will find it more 
convenient to buy the bundle proposed by firm 1 than the combination offered by rivals. However, as there are consumers potentially interested only in one good, or willing to purchase more than one unit of each good, the quantity of bundles sold by firm 1 is lower than the sum of separate variants sold by firms 2 and 3 .

Finally, plugging (81)-(82) and (84)-(85) in (78), (77) and (79), equilibrium profits under bundling are:

$$
\begin{gathered}
{ }_{b} \pi_{1}^{B}=\frac{(1-\gamma)(1+\delta)[4-\gamma(\gamma-2+4 \delta)-\delta(4-5 \delta)]^{2}}{8(1+\gamma+2 \delta)\left[2-\gamma(\gamma+2 \delta)+\delta\left(3-\delta-\delta^{2}\right)\right]^{2}} \\
{ }_{b} \pi_{i}^{B}=\frac{(1-\gamma)(1+\delta)(2+\gamma+3 \delta)^{2}\left[2(1+\delta)-(\gamma+\delta)^{2}\right]}{8(1+\gamma+2 \delta)\left[2-\gamma(\gamma+2 \delta)+\delta\left(3-\delta-\delta^{2}\right)\right]^{2}}, i=2,3 .
\end{gathered}
$$

Under the restrictions of Lemma $3{ }_{b} \pi_{1}^{B}>{ }_{b} \pi_{i}^{B}$, while ${ }_{b} \pi_{1}^{B}>{ }_{b} \pi_{2}^{B}+{ }_{b} \pi_{3}^{B}$ only when consumers perceive a high degree of product substitutability. ${ }^{11}$ This confirms what already highlighted in Lemma 2 and 4, i.e. that the profit of the multi-product firm is higher than the individual profit of its rivals, while it is lower than their sum for sufficiently high values of product differentiation.

Moreover, and of great interest for the purpose of the paper, a careful inspection at (87)- (88) vis-à-vis (71)- (72) reveals that under Bertrand competition the bundling strategy does produce a change in the equilibrium profits. It is therefore possible to evaluate whether the multi-product firm 1 has an incentive to bundle, and the potential effect on the rivals' profits. First of all, by comparing (87) with (71), I can prove that:

Proposition 3 Under Bertrand competition, the multi-product firm opts for bundling when $\gamma+\delta>0$, i.e. when the degree of substitutability between its products and those produced by the rivals is sufficiently high, and/or when the degree of product complementarity between any $A$ and $B$ is sufficiently low.

Proof: See the Appendix.

This result is very interesting as it shows that in presence of price competition bundling affects consumer's decision even when the multi-product firm ties its product on a $1-1$ ratio. The decision about whether to bundle or not depends on the balance between the degree of product substitutability and the degree of product

\footnotetext{
${ }^{11}$ More precisely,

$$
{ }_{b} \pi_{1}^{B}>{ }_{b} \pi_{2}^{B}+{ }_{b} \pi_{3}^{B} \text { when } \gamma>\frac{2+3 \delta(1-\delta)-\sqrt{2\left\{2+\delta\left[3+\delta\left(1+\delta+\delta^{2}\right)\right]\right\}}}{\delta-3}
$$
}

whose graphical representation is indeed similar to $\gamma_{2}$ and $\gamma_{4}$. 
complementarity characterizing market competition. The derivatives of (87) and (71) w.r.t. $\gamma$ and $\delta$ confirm that a reduction in the degree of both product differentiation and product complementarity lowers the profit of firm 1: $\partial_{b} \pi_{1}^{B} / \partial \gamma<0$ and $\partial_{b} \pi_{1}^{B} / \partial \delta<0 ; \partial \pi_{1}^{B} / \partial \gamma<0$ and $\partial \pi_{1}^{B} / \partial \delta<0$. Nonetheless, the multi-product firm 1 can use the bundling strategy to dampen such negative effects, given that:

$$
\left|\frac{\partial_{b} \pi_{1}^{B}}{\partial \gamma}\right|<\left|\frac{\partial \pi_{1}^{B}}{\partial \gamma}\right| \text { and }\left|\frac{\partial_{b} \pi_{1}^{B}}{\partial \delta}\right|<\left|\frac{\partial \pi_{1}^{B}}{\partial \delta}\right| .
$$

Bundling acts therefore as (i) a product-differentiation device, when product substitutability between the varieties of $A$ and $B$ produced by firm 1 and those produced by its rivals increases; (ii) a complementarity-enforcing tool, when the degree of complementarity between any $A$ and $B$ is low. By forcing consumers to buy $A_{1}$ and $B_{1}$ together, the multi-product firm is therefore able to reduce the profit loss induced by higher levels of both $\gamma$ and $\delta$.

Indeed, when comparing firm 1's equilibrium prices and quantities in the two scenarios, while it obviously always holds that ${ }_{b} p_{A B_{1}}^{B}>p_{A_{1}}^{B}=p_{B_{1}}^{B}$ and ${ }_{b} q_{A B_{1}}^{B}>$ $q_{A_{1}}^{B}=q_{B_{1}}^{B}$, it is relatively easy to demonstrate that:

Corollary $1{ }_{b} p_{A B_{1}}^{B}>p_{A_{1}}^{B}+p_{B_{1}}^{B}$ and ${ }_{b} q_{A B_{1}}^{B}>q_{A_{1}}^{B}=q_{B_{1}}^{B}$ when $\gamma+\delta>0$.

Proof See the Appendix.

In the parametric region where $\gamma+\delta>0$, firm 1 sells more bundles (consisting of one unit of $A_{1}$ joint with one unit of $B_{1}$ ) than the individual sale of $A_{1}$ and $B_{1}$. Moreover, the price it charges for the bundle is higher than the sum of the prices of the two unbundled goods. This helps explaining why the multi-product firm opts for bundling.

It is relevant to investigate what happens to equilibrium prices, quantities and profits of the rivals when the multi-product firm decides to bundle.

Corollary 2 When the multi-product firm opts for bundling, rivals charge a higher price and sell a lower quantity than without bundling: ${ }_{b} p_{B_{2}}^{B}={ }_{b} p_{A_{3}}^{B}>p_{B_{2}}^{B}=$ $p_{A_{3}}^{B}$ and ${ }_{b} q_{B_{2}}^{B}={ }_{b} q_{A_{3}}^{B}<q_{B_{2}}^{B}=q_{A_{3}}^{B}$. Moreover, they gain in terms of profit only for very high values of product substitutability and/or very low values of product complementarity. In particular, ${ }_{b} \pi_{i}^{B}>\pi_{i}^{B}$ when $\gamma>\gamma_{5}$, where $\gamma_{5}>-\delta$ and $\partial \gamma_{5} / \partial \delta<0$; in the remaining interval region, firm 2 and 3 incur in a profit loss.

Proof: See the Appendix. 
As a consequence, not only the bundling firm, but also its two symmetric rivals are able to raise their price in equilibrium. This is not surprising, as Bertrand's reaction functions are upward sloping. However, being single-product, their market share shrinks. Turning to profit's evaluation, the above corollary specifies that firms 2 and 3 gain under bundling only when $\gamma>\gamma_{5}(>-\delta)$, i.e. when the goods that they produce are perceived by consumers as very similar to those produced by the multi-product firm 1. This happens because the (positive) price difference overcomes in absolute value the (negative) quantity difference:

$$
\left|{ }_{b} p_{B_{2}}^{B}-p_{B_{2}}^{B}\right|>\left|{ }_{b} q_{B_{2}}^{B}-q_{B_{2}}^{B}\right|
$$

and similarly for firm 3 . In addition, as $\partial \gamma_{5} / \partial \delta<0$, the lower the product complementarity, the lower the degree of product substitutability required for the condition $\gamma>\gamma_{5}$ to hold.

The main results appearing in Proposition 3 and Corollary 2 are represented in Figure $\mathrm{B}$, where the threshold values of $\gamma$ partition the parameter space $\delta \in(-1,0)$ and $\gamma \in(0,1)$ in three areas of interest, given that the dashed area in $\gamma \in\left(0, \gamma_{3}\right)$ has no economic meaning, following Lemma 3.

Figure B : Bundling vs. No Bundling in Bertrand competition

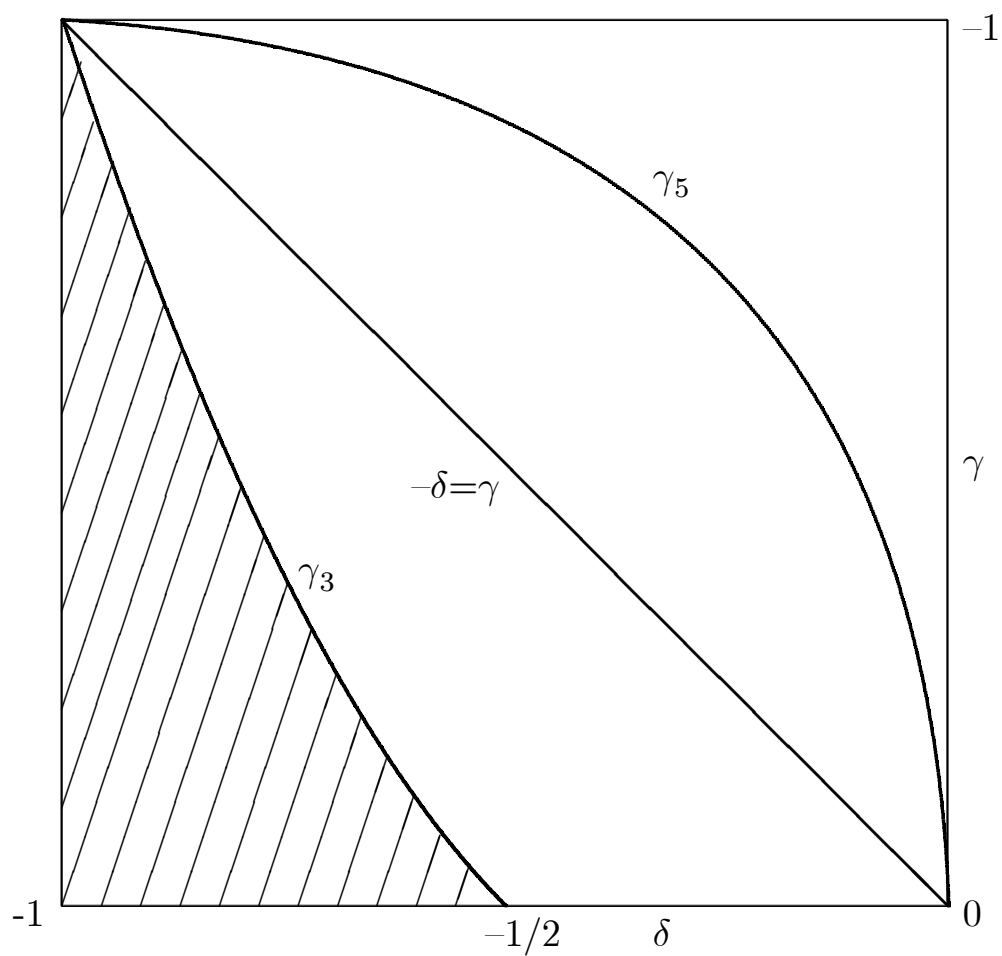


In $\gamma \in\left(\gamma_{3},-\delta\right)$ bundling is not selected at equilibrium by firm 1 as $\gamma<-\delta$. On the contrary, in the north-east parametric semi-space where $\gamma>-\delta$, firm 1 opts for bundling and the rivals enjoy a higher profit than without bundling only when $\gamma \in\left(\gamma_{5}, 1\right)$, while in $\gamma \in\left(-\delta, \gamma_{5}\right)$ their profit are lower.

These results are in line with Denicolò (2000), who shows that: (i) pure bundling can be profitable for the multiproduct/generalist firm when product substitutability across components increases and that (ii) the specialist/single-product firm may lose under bundling. However, in my model I can represent the situation in which the two goods do not have to be combined together for a 'system' to function; additionally, using my approach it is possible to capture the interaction between product substitutability and product complementarity in driving the decision to bundle for the multi-product firm.

\subsection{Welfare implications}

Compared to the situation where bundling was absent, the price per bundle charged by the multi-product firm is higher than the sum of the prices of the two unbundled goods, but the total amount of goods sold in the market increases. Rivals increase their prices as well, but their output shrinks. The impact for consumer surplus deserves therefore additional scrutiny.

First of all, consumer surplus for the Bertrand case in absence of bundling can be obtained from (29) and amounts to:

$$
C S^{B}=\frac{(1+\delta) \cdot \Gamma}{(1+\gamma+2 \delta)\left\{4-\gamma^{2}(1+\gamma)+\delta(2+\delta)(1-6 \delta)+\gamma[4+\delta(4+5 \delta)]\right\}^{2}},
$$

where

$$
\begin{aligned}
\Gamma= & 2(1+\gamma)^{2}(2+\gamma)^{2}+6(1+\gamma)^{2}(2+\gamma) \delta-3(1+\gamma)\left(13+\gamma(10+\gamma) \delta^{2}+\right. \\
& -2 \delta^{3}[29+\gamma(38+5 \gamma)]+24 \delta^{4}(2+\gamma)+72 \delta^{5}
\end{aligned}
$$

On the other hand, when firm 1 opts for bundling, consumer surplus derives from (73) and is given by:

$$
{ }_{b} C S^{B}=\frac{(1+\delta)}{16(1+\gamma+2 \delta)\left[2-\gamma(\gamma+2 \delta)+\delta\left(3-\delta-\delta^{2}\right)\right]^{2}} \cdot \Delta
$$

where:

$$
\begin{aligned}
\Delta= & 32+3 \gamma^{5}+\gamma^{4}(1+24 \delta)+2 \gamma^{2}\{\delta[\delta(56 \delta-27)-52]-8\}+\gamma^{3}\left(74 \delta^{2}-20-8 \delta\right)+ \\
& +\delta\left\{112+\delta(76+\delta[\delta(32 \delta-55)-80]\}+\gamma\left[32-\delta(2-\delta)\left(87 \delta^{2}+78 \delta-4\right)\right] .\right.
\end{aligned}
$$


It is relatively easy to demonstrate that $C S^{B}>0$ and ${ }_{b} C S^{B}>0$ in the interval region under consideration, as both the values of $\Gamma$ and $\Delta$ are positive in $\gamma \in\left(\gamma_{3}, 1\right)$, as well as $(1+\gamma+2 \delta)$. Finally, by comparing (91) with (92), one can find that:

Lemma 5 In the relevant interest region $\gamma \in\left(\gamma_{3}, 1\right)$, consumers always lose when firm 1 decides to bundle, as ${ }_{b} C S^{B}<C S^{B}$.

Proof: See the Appendix.

The above lemma highlights the detrimental effect of the bundling activity on consumer surplus, mainly due to the surge of prices. An antitrust authority focusing exclusively on consumer protection should therefore intervene when it detects the strategy adopted by the multi-product firm to sell both goods in a unique package.

However, the results of the previous subsection indicate that the multi-product firm can reduce the profit loss induced by higher levels of product substitutability and/or lower levels of product complementarity by resorting to bundling. In addition, there exists an interval region where also the rivals gain in terms of profits. It follows that the potential effect of bundling on social welfare, defined as the sum of consumer surplus and firms' profits, is at least ambiguous.

The total welfare in the two cases is respectively given by:

$$
\begin{gathered}
S W^{B}=C S^{B}+\pi_{1}^{B}+\pi_{2}^{B}+\pi_{3}^{B}, \\
{ }_{b} S W^{B}={ }_{b} C S^{B}+{ }_{b} \pi_{1}^{B}+{ }_{b} \pi_{2}^{B}+{ }_{b} \pi_{3}^{B},
\end{gathered}
$$

whose complete expressions are reported in the Appendix. An analytical evaluation of the difference between social welfare with and without bundling reveals that:

Proposition 4 In the relevant interest region, bundling always reduces social welfare, as ${ }_{b} S W^{B}<S W^{B}$ in $\gamma \in\left(\gamma_{3}, 1\right)$.

Proof: See the Appendix.

Now the result leaves no room for doubt, at least for the theoretical framework described in my model. A policy maker should therefore prohibit the use of the bundling strategy adopted by a multi-product firm looking for shelter under the unfavorable circumstance of low product differentiation and scarce product complementarity. This sheds light on a partially neglected case for antitrust intervention: at a first sight, one may think that it is not worthy to investigate the situation in which the multi-product firm decides to bundle $A_{1}$ with $B_{1}$ when rivals provide very 
similar of both $A$ and $B$. A consumer particularly interested in buying only the good of type $A$ may simply resort to firm 3 and get $A_{3}$, whose characteristics are very similar to those of $A_{1}$. However, and this is the crucial point, as bundling increases both the price of the bundle and that of $A_{3}$, the consumer will face a significant drop in his surplus. In aggregate, moreover, this brings to an overall reduction of total welfare.

\section{Conclusions and extensions}

This paper analyzed the effect of bundling by a multi-product firm that produces two complement goods and competes with single-product firms each producing a differentiated version of its products. The two complement goods do not have to be consumed together and the combination of those produced by the multi-product firm does not yield a higher quality with respect to the combination of those produced by the rivals. The aim was to show the strategic effect of bundling in a scenario in which the only asymmetry is the number of goods produced by the multi-product firm.

I started by expanding the contribution by Martin (1999) to prove that in his context bundling is ineffective when one introduces competition on both markets served by the multi-product firm. Another limitation of Martin's model is that it allows to consider only Cournot competition, while I wanted to investigate the effect of bundling also under Bertrand competition. For these reasons, I had to introduce a specific social welfare function; then I computed the equilibrium profits under both competition regimes and evaluated the incentive for the multi-product firm to bundle its products.

Under quantity competition, I demonstrated that the multi-product firm reacts better than rivals in front of lower levels of product differentiation. However, it does not earn additional profits by selling the two goods in a package. The situation is different under price competition, as bundling becomes profitable for sufficiently high levels of product substitutability combined with a relatively low degree of product complementarity. As profits in general suffer from a decrease in both the level of product differentiation and that of product complementarity, the multi-product firm can resort to bundling to reduce such a drop in profits. As for the rivals, they also may experience a positive impact on profits when the multi-product firm bundles, but this happens only for very high values of product substitutability combined with very low values of product complementarity, otherwise they incur in a profit loss. 
One of the consequences of the bundling strategy adopted by the multi-product firm is that not only its prices, but also those charged by the rivals increased, thus reducing consumer surplus and calling for the intervention of the regulator. When evaluating social welfare, I showed that the loss in consumer surplus is higher than the overall gain for firms, thus justifying the intervention of the antitrust agency when bundling is detected. It is worth noting that in my model bundling has a negative effect on welfare even in absence of entry-deterrence considerations. As a further research on the field, it would be interesting to study the role played by bundling as a barrier to entry when single product firms have to pay an entry cost when entering a market dominated by the multi-product firm.

The model presented can also be expanded in other directions. First of all, one can think of two multi-product firms competing in the same markets and study their incentive to bundle, and the consequences for social welfare. Second, one might introduce asymmetries in the degree of substitutability between different varieties of the same good and/or complementarity between complements goods. However, this could lead to a significant complication of the algebraic expressions of the model and probably not result in analytical solutions.

\section{Appendix}

\section{Proof of Lemma 1}

Consider the common denominator of equilibrium quantities (42) and (43):

$$
\begin{gathered}
{[4-\gamma(\gamma-2 \delta)+\delta(6+\delta)]>0} \\
\text { when } \gamma \in\left(-\delta-\sqrt{2\left(2+3 \delta+\delta^{2}\right)},-\delta+\sqrt{2\left(2+3 \delta+\delta^{2}\right)}\right) .
\end{gathered}
$$

However, the bigger root lies outside the parameter interval $\gamma \in(0,1)$ given that $-\delta+\sqrt{2\left(2+3 \delta+\delta^{2}\right)}>1$ in $\delta \in(-1,0)$. On the contrary, the smaller root $(-\delta-$ $\sqrt{2\left(2+3 \delta+\delta^{2}\right)} \in(0,1)$ when $\delta<\sqrt{5}-3$, otherwise it is always negative. As a consequence, taking into account that $\gamma \in(0,1)$ and $\delta \in(-1,0)$, the denominator is positive when:

(i) $\delta \geq(\sqrt{5}-3)$;

(ii) $\gamma>-\delta-\sqrt{2\left(2+3 \delta+\delta^{2}\right)}$ when $\delta<(\sqrt{5}-3)$ 
As for the numerator of (42) and (43):

$$
\begin{gathered}
(2-\gamma)>0 \text { always in } \gamma \in(0,1) \\
(2-\gamma+\delta)>0 \text { always in } \gamma \in(0,1) \text { and } \delta \in(-1,0)
\end{gathered}
$$

Notice that $(2-\gamma+\delta)>0$ requires that the very peculiar case where $\gamma=1$ and $\delta=-1$ has to be disregarded. It follows that the equilibrium quantities when firms play the Cournot game in absence of bundling are positive when the common denominator is positive, i.e. always when (A2) holds and $\gamma \in(0,1)$ and $\delta \in(-1,0)$. For notational purposes: $\gamma_{1}=-\delta-\sqrt{2\left(2+3 \delta+\delta^{2}\right)}$.

\section{Proof of Lemma 3}

Second-order conditions are negative iff

$$
\begin{gathered}
\frac{\left(1+\gamma-2 \delta^{2}\right)}{(1+\gamma+2 \delta)}>0 \Longleftrightarrow \\
\Longleftrightarrow\left\{\begin{array}{c}
(i) \gamma \in\left(0,2 \delta^{2}-1\right) \cup \gamma \in(-2 \delta-1,1) \text { when } \delta \in(-1,-\sqrt{2} / 2) ; \\
(i i) \gamma \in(-2 \delta-1,1) \text { when } \delta \in(-\sqrt{2} / 2,-1 / 2) ; \\
\text { (iii) always when } \delta \in(-1 / 2,0) .
\end{array}\right.
\end{gathered}
$$

where $-2 \delta-1>2 \delta^{2}-1$ in $\delta \in(-1,0)$. Furthermore, global stability for the system entails the evaluation of the $4 \times 4$ Hessian matrix, which is negative definite when its principal minors alternate in sign. It can be demonstrated that this happens only when $\gamma \in(-2 \delta-1,1)$; it follows that the interval region $\gamma \in\left(0,2 \delta^{2}-1\right)$ appearing in case $(i)$ does not provide globally stable solutions. Additionally, equilibrium prices (67) and (68) are positive only when $\gamma \in(-2 \delta-1,1)$, whereas they would take a negative value in $\gamma \in\left(0,2 \delta^{2}-1\right)$. Stability conditions and non-negativity of equilibrium prices indicate therefore to limit the parametric region of interest to the interval $\gamma \in\left(\gamma_{3}, 1\right)$, where $\gamma_{3}=-2 \delta-1 .^{12}$

\section{Proof of Proposition 3}

By comparing (87) with (71) and rearranging, it results that:

$$
{ }_{b} \pi_{1}^{B}-\pi_{1}^{B} \propto(\gamma+\delta)(1+\gamma+2 \delta)(2+\gamma+3 \delta) \cdot \chi
$$

\footnotetext{
${ }^{12}$ Additional calculations are available upon request. However, as they imply algebraic expressions which have been evaluated through Mathematica, I decided not to write their explicit expression in the text.
} 


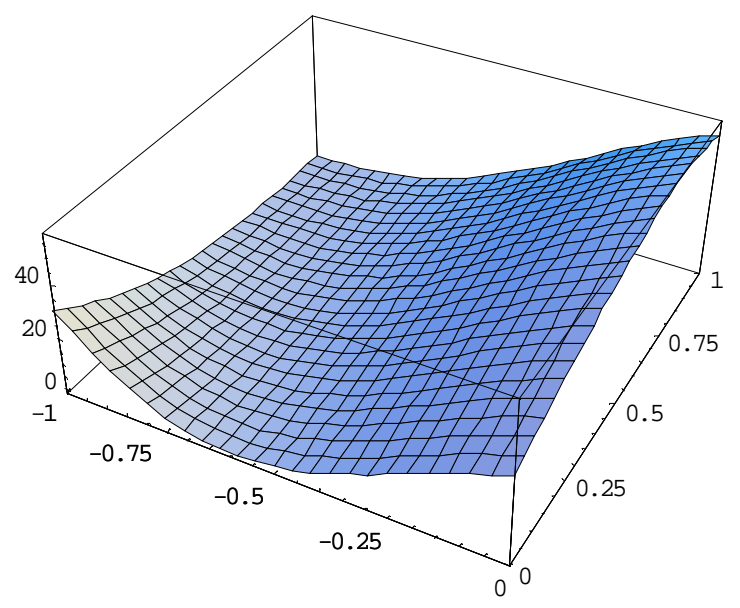

Figure 1: Value of $\chi$ in $\delta \in(-1,0)$ and $\gamma \in(0,1)$

where:

$$
\begin{aligned}
\chi= & 32+\gamma\left[48+\gamma^{2}\left(\gamma^{2}-5 \gamma-22\right)\right]+48 \delta-2 \gamma \delta(4-\gamma)[2 \gamma(1+\gamma)-5]+ \\
& +2 \delta^{2}[\gamma(15 \gamma-13)-56]-2 \delta^{3}[\gamma(9 \gamma-34)+79]+\delta^{4}(55-\gamma)+54 \delta^{5} .
\end{aligned}
$$

Under Lemma 3, i.e. in $\gamma \in\left(\gamma_{3}, 1\right),(1+\gamma+2 \delta)>0$ and $(2+\gamma+3 \delta)>0$; moreover, $\chi>0$ in the relevant parameter region, as it can be seen in Figure 1. As a consequence, ${ }_{b} \pi_{b_{1}}^{B}>\pi_{1}^{B}$ when $(\gamma+\delta)>0$, or $\gamma>-\delta$.

\section{Proof of Corollary 1}

Take into account (81) vs. (67) and (84) vs. (69):

$$
\begin{gathered}
{ }_{b} p_{A B_{1}}^{B}-\left(p_{A_{1}}^{B}+p_{B_{1}}^{B}\right) \propto(\gamma+\delta)(1+\gamma+2 \delta)(2+\gamma+3 \delta) . \\
{ }_{b} q_{A B_{1}}^{B}-q_{A_{1}}^{B}={ }_{b} q_{A B_{1}}^{B}-q_{B_{1}}^{B} \propto(\gamma+\delta)(2+\gamma+3 \delta) .
\end{gathered}
$$

As noticed above, in $\gamma \in\left(\gamma_{3}, 1\right),(1+\gamma+2 \delta)>0$ and $(2+\gamma+3 \delta)>0$. It follows that ${ }_{b} p_{A B_{1}}^{B}>\left(p_{A_{1}}^{B}+p_{B_{1}}^{B}\right)$ and ${ }_{b} q_{A B_{1}}^{B}>q_{A_{1}}^{B}$ when $(\gamma+\delta)>0$, or $\gamma>-\delta$.

\section{Proof of Corollary 2}

Consider (82) vs. (68) and (85) vs. (70). It is relatively simple to find that:

$$
{ }_{b} p_{B_{2}}^{B}-p_{B_{2}}^{B}={ }_{b} p_{A_{3}}^{B}-p_{A_{3}}^{B} \propto(1+\gamma+2 \delta)(2+\gamma+3 \delta),
$$


which is always positive in the region of interest, as already discussed, while

$$
{ }_{b} q_{B_{2}}^{B}-q_{B_{2}}^{B}={ }_{b} q_{A_{3}}^{B}-q_{A_{3}}^{B} \propto(2+\gamma+3 \delta)[\gamma(\gamma+2 \delta)-2-\delta(4+\delta)],
$$

where $[\gamma(\gamma+2 \delta)-2-\delta(4+\delta)]<0$ in $\gamma \in\left(\gamma_{3}, 1\right)$. It follows that, under the conditions introduced in Lemma $3,{ }_{b} p_{B_{2}}^{B}={ }_{b} p_{A_{3}}^{B}>p_{B_{2}}^{B}=p_{A_{3}}^{B}$ and ${ }_{b} q_{B_{2}}^{B}={ }_{b} q_{A_{3}}^{B}<$ $q_{B_{2}}^{B}=q_{A_{3}}^{B}$.

The comparison between (88) and (72) appear as more cumbersome than the previous ones as:

$$
\begin{gathered}
{ }_{b} \pi_{i}^{B}-\pi_{i}^{B} \propto-\gamma^{4}(1-s)+2 \gamma^{2}[1-\delta(2+3 \delta)]+4 \gamma \delta\left[\delta\left(5 \delta+10 \delta^{2}-2\right)-1\right]+ \\
+\delta\left[8+6 \delta+\delta^{2}\left(\delta^{2}-7 \delta-16\right)\right], i=2,3
\end{gathered}
$$

However, it is possible to find a threshold value of $\gamma$ such that:

$$
{ }_{b} \pi_{i}^{B}>\pi_{i}^{B} \text { when } \gamma>\gamma_{5} .
$$

The precise expression of $\gamma_{5}$ is omitted for brevity but it is represented in Figure B. ${ }^{13}$ Numerical and graphical simulations confirm that $\gamma_{5} \in(-\delta, 1)$, i.e. it belongs to the area where bundling is selected at equilibrium. Moreover, comparative statics entail that $\partial \gamma_{5} / \partial \delta<0$ : the higher the value of the parameter inversely measuring product complementarity, the lower the value of $\gamma$ necessary to satisfy (A11). This implies that firms 2 and 3 gain from the bundling strategy adopted by firm 1 for a combination of sufficiently high value of $\gamma$ and $\delta$.

\section{Proof of Lemma 5}

Taking (91) and (92) and then evaluating ${ }_{b} C S^{B}$ vs. $C S^{B}$ it is possible to obtain that:

$$
{ }_{b} C S^{B}-C S^{B}=\frac{(1+\delta)}{16(1+\gamma+2 \delta)} \cdot \Xi,
$$

where $\Xi=\frac{\Delta\left\{4-\gamma^{2}(1+\gamma)+\delta(2+\delta)(1-6 \delta)+\gamma[4+\delta(4+5 \delta)]\right\}^{2}-16 \Gamma\left[2-\gamma(\gamma+2 \delta)+\delta\left(3-\delta-\delta^{2}\right)\right]^{2}}{\left[2-\gamma(\gamma+2 \delta)+\delta\left(3-\delta-\delta^{2}\right)\right]^{2}-\left\{4-\gamma^{2}(1+\gamma)+\delta(2+\delta)(1-6 \delta)+\gamma[4+\delta(4+5 \delta)]\right\}^{2}}$.

In the relevant interval region $\gamma \in\left(\gamma_{3}, 1\right)$, it follows that ${ }_{b} C S^{B}-C S^{B} \propto \Xi$. Figure 2 represents $\Xi$ in $\delta \in(-1,0)$ and $\gamma \in(0,1)$, thus revealing that ${ }_{b} C S^{B}-C S^{B}<$ 0 .

\footnotetext{
${ }^{13}$ Also in this case the very long and tedious algebraic expressions have been evaluated with Mathematica and not included in the text, but they are available upon request.
} 


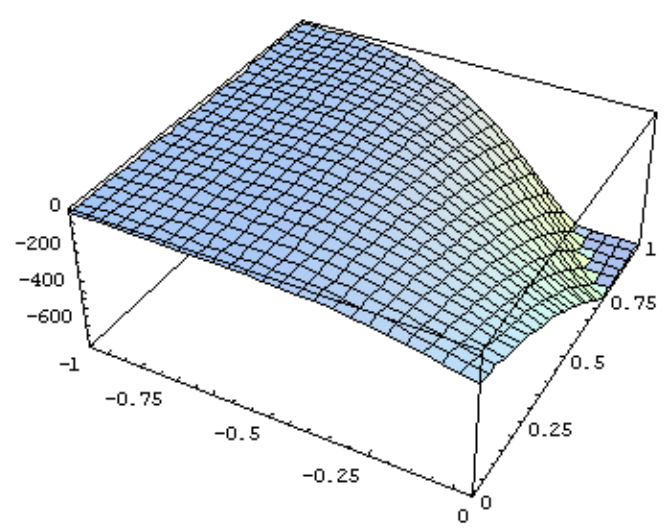

Figure $2:{ }_{b} C S^{B}-C S^{B}$ in $\delta \in(-1,0)$ and $\gamma \in(0,1)$

\section{Proof of Proposition 4}

Total welfare in Bertrand without bundling is given by:

$$
\begin{aligned}
S W^{B} & =C S^{B}+\pi_{1}^{B}+\pi_{2}^{B}+\pi_{3}^{B}= \\
& =\frac{2(1-\delta) \cdot \Theta+(1+\delta) \cdot \Gamma}{(1+\gamma+2 \delta)\left\{4-\gamma^{2}(1+\gamma)+\delta(2+\delta)(1-6 \delta)+\gamma[4+\delta(4+5 \delta)]\right\}^{2}}
\end{aligned}
$$

where $\Theta=\left\{(1+\delta)\left[2+\gamma(3+\gamma)-6 \delta^{2}\right]^{2}+(1+\gamma-2 \delta)(2+\gamma+3 \delta)^{2}\left(1+\gamma-2 \delta^{2}\right)\right\}$.

When firm 1 is allowed to bundle, total welfare amounts to:

$$
\begin{aligned}
{ }_{b} S W^{B} & ={ }_{b} C S^{B}+{ }_{b} \pi_{1}^{B}+{ }_{b} \pi_{2}^{B}+{ }_{b} \pi_{3}^{B}= \\
& =\frac{(1+\delta)[2(1-\gamma) \Upsilon+\Delta]}{16(1+\gamma+2 \delta)\left[2-\gamma(\gamma+2 \delta)+\delta\left(3-\delta-\delta^{2}\right)\right]^{2}}
\end{aligned}
$$

where $\Upsilon=\left\{[4-\gamma(\gamma-2+4 \delta)-\delta(4-5 \delta)]^{2}+2(2+\gamma+3 \delta)^{2}\left[2(1+\delta)-(\gamma+\delta)^{2}\right]\right\}$. Both $S W^{B}$ and ${ }_{b} S W^{B}$ are positive in the interval region under consideration as they consist of the sum of positive components. Taking the difference:

$$
{ }_{b} S W^{B}-S W^{B}=\frac{1}{16(1+\gamma+2 \delta)} \cdot \Omega
$$

and considering $\gamma \in\left(\gamma_{3}, 1\right)$, it becomes evident that ${ }_{b} S W^{B}<S W^{B} \propto \Omega$, where: $\Omega=\frac{(1+\delta)[2(1-\gamma) \Upsilon+\Delta]\left\{4-\gamma^{2}(1+\gamma)+\delta(2+\delta)(1-6 \delta)+\gamma[4+\delta(4+5 \delta)]\right\}^{2}-16[2(1-\delta) \cdot \Theta+(1+\delta) \cdot \Gamma]\left[2-\gamma(\gamma+2 \delta)+\delta\left(3-\delta-\delta^{2}\right)\right]^{2}}{\left[2-\gamma(\gamma+2 \delta)+\delta\left(3-\delta-\delta^{2}\right)\right]^{2}-\left\{4-\gamma^{2}(1+\gamma)+\delta(2+\delta)(1-6 \delta)+\gamma[4+\delta(4+5 \delta)]\right\}^{2}}$.

Figure 3 shows that $\Omega<0$ in $\delta \in(-1,0)$ and $\gamma \in(0,1)$. A fortiori, this will hold also in the interval region of interest, thus demonstrating that ${ }_{b} S W^{B}<S W^{B}<0$. 


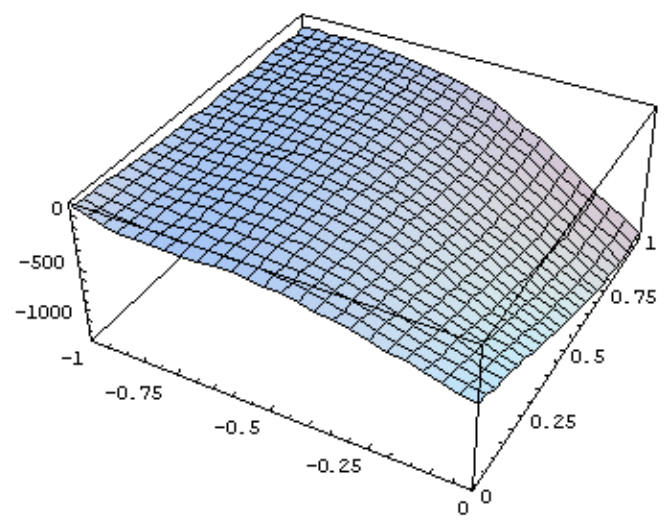

Figure $3:{ }_{b} S W^{B}-S W^{B}$ in $\delta \in(-1,0)$ and $\gamma \in(0,1)$

\section{References}

[1] Adams, W. and J. Yellen (1976), Commodity Bundling and the Burden of Monopoly, Quarterly Journal of Economics, XC, 475-498.

[2] Bakos, Y. and E. Brynjolfsson (1999), Bundling Information Goods: Pricing, Profits, and Efficiency, Management Science, 45, 1613-1630.

[3] Bowman, W. (1957), Tying arrangements and the leverage problem, Yale Law Journal, 67, 19-36.

[4] Brandenburger, A. and B. Nalebuff (1996), Co-opetition, Doubleday: New York.

[5] Carbajo, J., De Meza, D. and D.J. Seidman (1990), A strategic motivation for commodity bundling, Journal of Industrial Economics, 38, 283-298.

[6] Carlton, D. and M. Waldman (2002), The Strategic Use of Tying to Preserve and Create Market Power in Evolving Industries, RAND Journal of Economics, 47, 194-220.

[7] Casadesus-Masanell, R., Nalebuff, B. and D. B. Yoffie (2008). Competing Complements. Harvard Business School Working Paper, No. 09-009.

[8] Chen, Y. (1997), Equilibrium product bundling, Journal of Business, 70, 85103.

[9] Choi, J. P., (2004), Tying and Innovation: a Dynamic Analysis of Tying Arrangements, The Economic Journal, 114, 83-101. 
[10] Choi, J. P. (2008), Mergers with Bundling in Complementary Markets, Journal of Industrial Economics, 56, 553-577.

[11] Choi, J. P. and C. Stefanadis (2001), Tying, Investment, and the Dynamic Leverage Theory, RAND Journal of Economics, 32, 52-71.

[12] Cready, W. M. (1991), Premium Bundling, Economic Inquiry, 29, 173-79.

[13] Denicolò, V. (2000), Compatibility and Bundling with Generalist and Specialist Firms, Journal of Industrial Economics, 48, 177-188.

[14] Dixit, A. (1979), A model of duopoly suggesting a theory of entry barriers, Bell Journal of Economics, 10, 20-32.

[15] Economides, N. (1989), Desirability of Compatibility in the Absence of Network Externalities, American Economic Review, 79, 1165-1181.

[16] Economides, N. and S. C. Salop (1992), Competition and Integration among Complements, and Network Market Structure, Journal of Industrial Economics, 40, pp. $105-123$.

[17] Farrell, J., Monroe, H. K. and G. Saloner (1998), The Vertical Organization of Industry: Incompatibility versus Compatibility, Journal of Economics and Management Strategy, 7, 143-182.

[18] Gans, J. S. and S. P. King (2006), Paying for Loyalty: Product Bundling in Oligopoly, Journal of Industrial Economics, 54, 43-62.

[19] Martin, S. (1999), Strategic and welfare implications of bundling, Economics Letters, 62, 371-376.

[20] Matutes, C. and P. Regibeau (1988), Mix and Match: Product Compatibility Without Network Externalities, Rand Journal of Economics, 19, 221-234.

[21] Matutes, C. and P. Regibeau (1992), Compatibility and Bundling of Complementary Goods in a Duopoly, Journal of Industrial Economics, 40, 37-54.

[22] McAfee, R. P., McMillian, J. and M. D. Whinston (1989), Multiproduct monopoly, commodity bundling, and correlation of values, Quarterly Journal of Economics, 104, 371-384.

[23] Nalebuff, B. (2004), Bundling as an Entry Barrier, Quarterly Journal of Economics, 119, 159-187. 
[24] Posner, R. A. (1976), Antitrust Law: an Economic Perspective, Chicago: University of Chicago Press.

[25] Schmalensee, R. L. (1982), Commodity Bundling by Single-Product Monopolies, Journal of Law and Economics, XXV, 67-71.

[26] Schmalensee, R. L. (1984), Gaussian demand and commodity bundling, Journal of Business, $\mathbf{5 7}, 58-73$.

[27] Spence, A.M. (1976), Product differentiation and welfare, American Economic Review, 66, 407-414.

[28] Stigler, G. (1968), A Note on Block Booking, in J. Stigler, ed., The Organization of Industries (Homewood, IL: Irwin), 837-859.

[29] Whinston, M. D. (1990), Tying, Foreclosure, and Exclusion, American Economic Review, 80, 837-859. 